\title{
Intercomparing the Response of Tropospheric and Stratospheric Temperature to Two Types of El Niño Onset
}

\author{
Shujie Chang, ${ }^{1}$ Min Shao, ${ }^{1}$ Chunhua Shi, ${ }^{2}$ and Hua $\mathrm{Xu}^{1}$ \\ ${ }^{1}$ College of Ocean and Meteorology, Guangdong Ocean University, Zhanjiang, Guangdong, China \\ ${ }^{2}$ Earth System Modeling Center, Key Laboratory of Meteorological Disaster, Nanjing University of Information Science and Technology, \\ Nanjing, Jiangsu, China
}

Correspondence should be addressed to Shujie Chang; changshujiebeauty@163.com and Min Shao; mshao@masonlive.gmu.edu Received 14 May 2017; Revised 19 June 2017; Accepted 19 July 2017; Published 27 August 2017

Academic Editor: Jia Yue

Copyright (C) 2017 Shujie Chang et al. This is an open access article distributed under the Creative Commons Attribution License, which permits unrestricted use, distribution, and reproduction in any medium, provided the original work is properly cited.

\begin{abstract}
Based on Remote Sensing Systems-retrieved temperature data in the period of January 1979 to February 2016, the response of stratospheric and tropospheric temperature in boreal winter to two previously defined types of El Niño [spring (SP) and summer $(\mathrm{SU})]$ is investigated. The results show that, the response of temperature under SP onset involves a significant positive anomaly, with a symmetric distribution about the equator over the Indian Ocean region in the lower troposphere $(850 \mathrm{hPa})$ and a negative anomaly in the lower stratosphere $(50 \mathrm{hPa})$. Meanwhile, in the area $30^{\circ} \mathrm{N}$ and $30^{\circ} \mathrm{S}$ of the equator, most parts of the lower stratosphere feature a positive anomaly. This indicates that SP El Niño events are more conducive than SU events to warming the lower stratosphere. The atmospheric circulation structure over the tropical Indian Ocean is beneficial to the upward transfer of warm air to the upper layer. In contrast, the structure over the tropical Pacific Ocean favors the warming of upper air. On the other hand, the Eliassen-Palm (EP) flux is small and the heat flux is negative during SP-type events. Thus, the EP flux and Brewer-Dobson circulation decrease, making the temperature higher in the upper troposphere-lower stratosphere region at low latitudes.
\end{abstract}

\section{Introduction}

The El Niño-Southern Oscillation (ENSO) is the strongest annual-scale air-sea interaction phenomenon in the tropical Pacific. It is considered the strongest signal of annual climate change, which has an important impact on global tropospheric weather and climate $[1,2]$. Recent research suggests that lower sea surface temperature anomalies (SSTAs) will contribute to change in upper atmospheric circulation. SSTAs mainly affect the wave propagation in the stratospheric and tropospheric atmosphere during ENSO events. Moreover, cold and warm ENSO SSTA events have their own respective characteristics in the stratosphere [3]. Therefore, different types of El Niño events will affect tropospheric and stratospheric temperature in different ways. Describing and understanding the atmospheric processes in the stratosphere and troposphere, as well as their linkages and interaction, are important when investigating the response of temperature to El Niño events.
Before the 1980s, research on tropospheric and stratospheric temperature relied upon regional cases, such as the concept of residual circulation put forward by Brewer and Dobson, which is the vertical meridional circulation of the troposphere and stratosphere from the equator to the poles [4]. Now termed Brewer-Dobson circulation, this phenomenon is used to explain the vertical meridional distribution of water vapor and ozone in the stratosphere. From the 1980s, meteorologists began to understand the interaction between the upper and lower atmosphere and carried out research on the stratosphere and troposphere from the perspective of regional, quantitative, and longterm variation. Ren et al. [5] studied the importance of the Tibetan Plateau on stratosphere-troposphere coupling by applying isentropic potential vorticity theory. With the help of a high-resolution Lagrangian transport model, Chen et al. [6] discussed the source regions, propagation paths, and timing of the movement of air mass from the stratosphere to troposphere in the Asian summer monsoon region. When 
it comes to the interaction between the stratosphere and troposphere and the SSTAs caused by ENSO, Taguchi and Hartmann [7] used an atmospheric chemistry-climate model to analyze the mechanism through which ENSO events affect the polar stratosphere, pointing out that the frequency of stratospheric sudden warming in El Niño years is twofold greater than in La Niña years. Meanwhile, Camp and Tung [8] demonstrated that, statistically, ENSO has an influence on the temperature of the Northern Hemisphere winter polar stratosphere; it generates temperatures of around $3.8 \mathrm{~K}$, which is equivalent to the quasi-biennial oscillation in the equatorial stratosphere's zonal wind. Gage and Reid [9] found that different phases of ENSO can cause a reversal of the temperature gradient at the top of the troposphere and, later, Reid et al. [10] pointed out that good positive and negative correlations exist between the temperature of the tropical lower stratosphere and the SST of the equatorial Pacific. Lastly, Yulaeva et al. [11] noted that the uppermost latitudinal asymmetric specification is the ENSO signal in the tropical lower stratospheric temperature field.

Previous research has indicated that strong ENSO events enhance tropical upwelling and stratosphere-troposphere exchange (STE). This change in upwelling and STE plays an important role in the atmospheric composition and structure of the upper troposphere-lower stratosphere (UTLS) region. Specifically, ENSO has an influence on the tropical lower stratosphere and UTLS region, albeit scientists are yet to agree on its extent and the differences among different types of ENSO.

Generally speaking, we mostly study El Niño from the perspective of geographical position, dividing ENSO into an eastern type and central type. However, according to the strength of the SSTAs over the eastern Pacific Ocean, El Niño events have also been divided into four levels $[12,13]$. In fact, the classification of El Niño events has been studied by many scientists [14-17]. In 1995, Wang pointed out that the onset of El Niño episodes is greatly affected by different climatic backgrounds of SST [18], and Xu and Chan [19] proved that El Niño events are very closely linked to the Asian-Australian monsoon. Therefore, classifying El Niño events based on their onset time offers clues in their study.

Many studies have investigated the effects of different types of the El Niño on tropopause and lower stratosphere. For example, Canonical El Niño and El Niño Modoki events can lead to profoundly different effects on stratospheric temperature and circulation [20-22]. This is because completely different patterns of propagation and dissipation of ultralong Rossby waves in the mid-latitude stratosphere are caused by the gradient patterns of SSTAs in the two types of El Niño events.

Specifically, Xu and Chan [19] put forward a new classification in which they divided El Niño events into the spring (SP) type (referring to the months of April and May) and the summer (SU) type (referring to the months after July), according to the first time that the Niño3.4 index exceeds 0.5. Characteristically, an SP-type El Niño is much stronger and more durable than an SU-type event. Because of the difference in the timing, intensity, and causes of these two types of El Niño, it follows that there is also likely to be a different tropospheric and stratospheric temperature response. We investigate this assertion in the present study.

\section{Data and Method}

2.1. Satellite Data. The Microwave Sounding Unit (MSU), carried onboard American polar orbiting satellites, and the Advanced MSU (AMSU) provide almost global coverage in their measurements of atmospheric temperature from Earth's surface to the lower stratosphere, throughout the entire day. Since it came into operation in 1978, this instrument has played a vital role in research on the variation of upper atmospheric temperature [23]. At present, there are three sets of long-term MSU data: one is compiled and qualitycontrolled by the University of Alabama in Huntsville; the second by the scientific research company Remote Sensing Systems (RSS); and the third by NOAA's National Environmental Satellite, Data, and Information Service and Center for Satellite Applications and Research [24].

Because RSS data provides us with the temperature information needed in the present study, we use monthly RSS data (ftp://ftp.ssmi.com $/ \mathrm{msu} / \mathrm{data} /$ ) at a resolution of $2.5^{\circ} \times 2.5^{\circ}$ on a global scale for the period of January 1979 to February 2016. These data include the temperature in the lower troposphere (TLT), the temperature in the middle troposphere (TMT), the temperature in the lower stratosphere (TLS), the temperature in the total troposphere (TTT), and the temperature in the total stratosphere (TTS), in the vertical direction. The TTT is calculated by a linear algorithm involving the TMT and TLS: $\mathrm{TTT}=1.1 \times \mathrm{TMT}-0.1 \times$ TLS . According to the suggestion made on the official website, we use version 4.0 of the TMT and TTT data and version 3.3 of the other data.

2.2. Niño3.4 Index. The Niño3.4 index data used in this study are from the monthly SSTA made available by the Climate Prediction Center (http://www.cpc.ncep.noaa.gov/) for the period 1950 to 2016.

2.3. Reanalysis Data. ERA-Interim data are used to analyze the circulation pattern and heat flux from January 1979 to February 2016. For the vertical direction, five representative heights are chosen: the lower troposphere $(700 \mathrm{hPa})$, the middle troposphere $(500 \mathrm{hPa})$, the upper troposphere $(200 \mathrm{hPa})$, the lower stratosphere $(100 \mathrm{hPa})$, and the stratosphere $(1 \mathrm{hPa})$. To analyze the circulation pattern, winter (December-January-February) monthly zonal and meridional wind fields are used, with a horizontal resolution of $1^{\circ} \times 1^{\circ}$. The SST has a horizontal resolution of $2.5^{\circ} \times 2.5^{\circ}$. Lastly, for heat flux analysis, the daily meridional wind field and temperature are used, with a horizontal resolution of $2.5^{\circ} \times 2.5^{\circ}$

2.4. Method. Composite analysis is the main method adopted in this study, with the $t$-test used to judge the statistical significance. Specifically, setting $\left(\overline{X_{1}}, \overline{X_{2}}\right)$ and $\left(s_{1}{ }^{* 2}, s_{2}{ }^{* 2}\right)$ as the average and variance of $X_{1}$ and $X_{2}$, respectively, when $\sigma_{1}=\sigma_{2}$, the statistic is $t=\left(\overline{X_{1}}-\overline{X_{2}}\right) /$ $\left(\sqrt{\left(\left(n_{1}-1\right) s_{1}{ }^{* 2}+\left(n_{2}-1\right) s_{2}{ }^{* 2}\right) /\left(n_{1}+n_{2}-2\right)} \sqrt{\left.1 / n_{1}+1 / n_{2}\right)} . \mathrm{A}\right.$ 
TABLE 1: Onset time and classification of El Niño events during 1978-2016.

\begin{tabular}{|c|c|c|c|c|c|c|}
\hline Sequence & Dates & Duration & Onset & Type & MAX_Ano & MAX_Mon \\
\hline 1 & 1982.05-1983.06 & 14 & 4 & SP & 2.21 & 12 \\
\hline 2 & 1991.06-1992.06 & 13 & 5 & SP & 1.65 & 1 \\
\hline 3 & 1994.10-1995.02 & 5 & 9 & SU & 1.14 & 12 \\
\hline 4 & 1997.05-1998.05 & 13 & 4 & SP & 2.32 & 11 \\
\hline 5 & 2002.06-2003.02 & 9 & 5 & SP & 1.26 & 11 \\
\hline 6 & 2004.07-2005.03 & 9 & 6 & SU & 0.78 & 1 \\
\hline 7 & 2006.09-2007.01 & 5 & 8 & SU & 1.02 & 12 \\
\hline 8 & 2009.09-2010.04 & 8 & 8 & SU & 1.36 & 1 \\
\hline 9 & 2015.04-2016.05 & 14 & 3 & SP & 2.33 & 1 \\
\hline
\end{tabular}

$t$ distribution with $v=n_{1}+n_{2}-2$ degrees of freedom is obeyed, which can be used to test the assumption that the two samples' population means are equal. Giving a reliability of $\alpha$ and $t \alpha$, when $t>t \alpha$, the assumption is false and is significantly different [25-27].

\section{Classification and Comparison of the Two Types of El Niño}

3.1. Classification. According to a classification method [19], the first time that the Niño3.4 index exceeds 0.5 is considered as the moment of El Niño onset. Furthermore, an El Niño event is classified as having happened when a Niño3.4 index in excess of 0.5 has occurred for at least six months. Additionally, El Niño events are divided into the SP type (i.e., spring: April and May) and the SU type (i.e., summer: after July). Removing the exception from 1986 to 1988 (duration too long), the El Niño types are classified as detailed in Table 1. In short, the SP events are 1982, 1991, 1997, 2002, and 2015 and the SU events are 1994, 2004, 2006, and 2009. For the composite analysis, the December of the year when the El Niño event begins and the corresponding January to February of the following year are used. For instance, for the SP-type El Niño from May 1982 to June 1983, the December of 1982 and the January to February of 1983 are employed.

3.2. Comparison. Figure 1 shows that the average Niño3.4 index from 1979 to 2016 is larger for SP-type events than SUtype events, and the difference can be more than 0.9. Apart from the SP-type event of 2002/03, all SP-type Niño3.4 index values are higher than the average value (green line), while the SU-type values are lower. In short, the SP-type El Niño events are stronger than the SU-type events.

To understand more clearly the differences between the two types of El Niño, the temporal evolution of SSTAs near the equator $\left(5^{\circ} \mathrm{S}-5^{\circ} \mathrm{N}\right)$ is composited (Figure 2), in which 0 stands for the year when the El Niño event happened and +1 stands for the following year. For the SP event (Figure 2(a)), positive SSTAs with a maximum value of $2.2^{\circ} \mathrm{C}$ appear near $110^{\circ} \mathrm{W}$, and the duration lasts from December to the January of the following year. The positive SSTAs are situated over the equatorial eastern Pacific Ocean near $170^{\circ} \mathrm{E}-60^{\circ} \mathrm{W}$. In this area, the onset time of the SP event begins around April. Meanwhile, the positive SSTAs persist in this area for

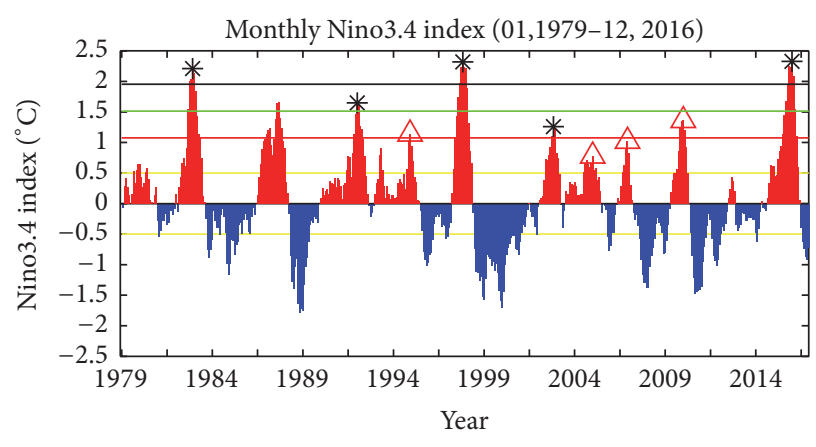

FIGURE 1: Niño3.4 index time series for SP-type (black asterisks) and SU-type (red triangles) El Niño events. The horizontal black (red) line indicates the mean value of the SP (SU) type. The horizontal green line indicates the mean value of all (SP and SU) events combined. The horizontal yellow lines indicate the \pm 0.5 index levels.

about 14 to 16 months and, at the same time, the equatorial eastern Pacific Ocean is dominated by negative SSTAs with a maximum value of -0.4 . The negative SSTAs persist in this area for about 12 months.

Of note is that positive SSTAs also exist over the equatorial Indian Ocean near $30^{\circ}-100^{\circ} \mathrm{E}$. The positive SSTAs with a maximum value of $0.6^{\circ}$ last from the December to the February of the following year.

For the SU event, positive SSTAs begin to appear near $170^{\circ} \mathrm{W}$ after June of the year when the El Niño occurs (Figure 2(b)) but are weaker than those of the SP event. Moreover, the maximum positive SSTAs are located farther east than those of the SP event. The positive SSTAs are situated over the equatorial central and eastern Pacific Ocean near $150^{\circ} \mathrm{E}-60^{\circ} \mathrm{W}$. In this area, the positive SSTAs persist for about 8 to 10 months, which is shorter than for the SP event. In addition, the east-west SST gradient is much weaker than that in the SP event.

\section{Response of Tropospheric and Stratospheric Temperature}

The temperature composites shown in Figure 3 for the troposphere and stratosphere, comprising SP El Niño events totaling 15 months in 5 years and SU El Niño events totaling 12 months in 4 years, show that the atmosphere from the 


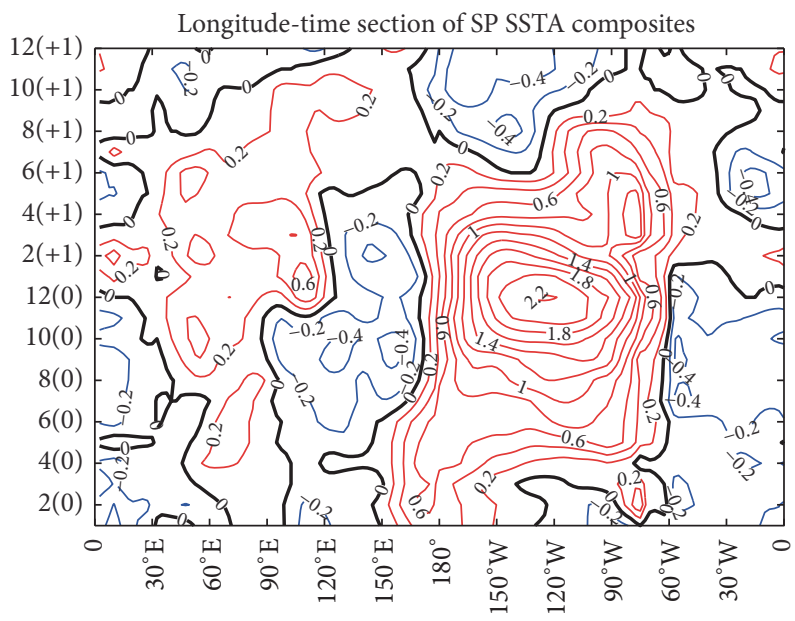

(a)

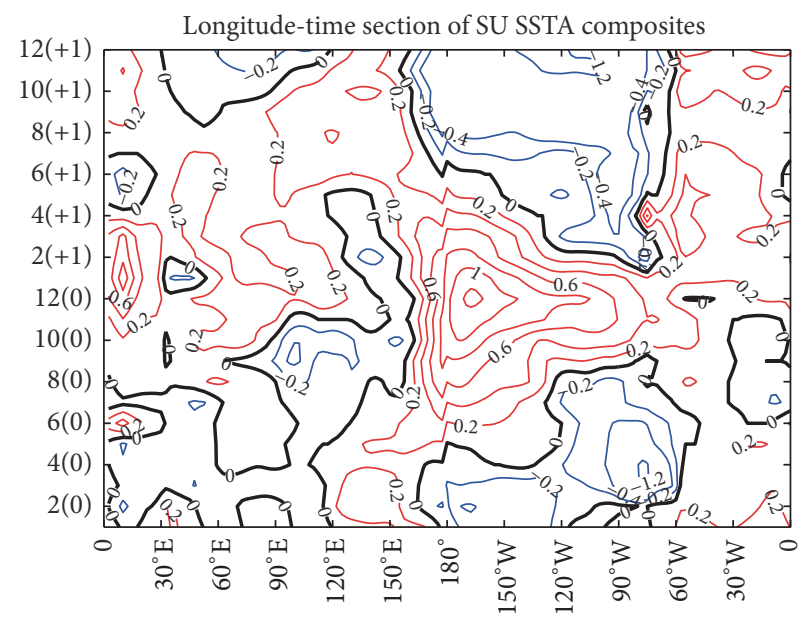

(b)

FIGURE 2: Longitude-time section of composite SSTA near the equator $\left(5^{\circ} \mathrm{S}-5^{\circ} \mathrm{N}\right)$ for (a) SP and (b) SU El Niño, in which the black contours indicate the mean value, the red contours indicate positive anomalies, and the blue contours indicate negative anomalies.

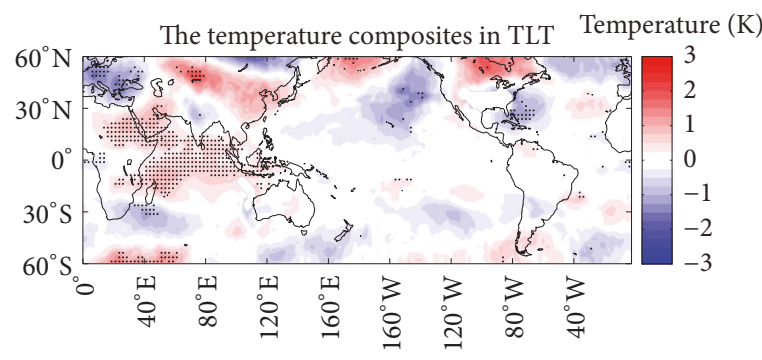

(a)

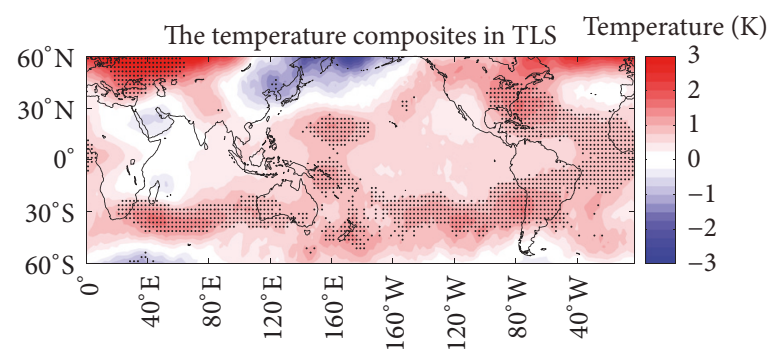

(b)

FIGURE 3: Winter (December-January-February) composites of the SP and SU temperature differences, in which black spots indicate that the differences are significant at the 95\% confidence level: (a) TLT; (b) TLS.

lower troposphere to the lower stratosphere is characterized by positive anomalies. This is based on a test area covering the whole of the equatorial Indian Ocean and suggests that SP-type events can warm the atmosphere on a larger scale than SU-type events in the troposphere and stratosphere during winter. Furthermore, this distribution of anomalies is symmetric about the equator. The value of the positive anomaly area is about $1.0 \mathrm{~K}$. The results of temperature composites in TMT and TTT are similar to the results of temperature composites in TLT, so Figure 3 only shows temperature composites in TLT.

In the lower stratosphere, the difference in the Indian Ocean region is not statistically significant but shows a negative anomaly that is symmetric about the equator. This means that SP-type events can cool the atmosphere more than SU-type events during winter, with the rate of cooling being about $0.5 \mathrm{~K}$. However, for the region $30^{\circ} \mathrm{N}$ and $30^{\circ} \mathrm{S}$ of the equator, most of the differences in the lower stratosphere are statistically significant, presenting as positive anomalies. This indicates that, apart from the equatorial Indian Ocean region, SP-type El Niño events are more conducive than SUtype events to warming the lower stratosphere.
As is known, the Indian Ocean SST is quite closely associated with the East Asian summer monsoon. The indication is that abnormal changes in the Indian Ocean SST are affected by the intensity and duration of ENSO, according to observations. On the one hand, SP- and SU-type El Niño events will affect the Indian Ocean SST, while, on the other hand, from the composite analysis presented here, SP- and SU-type events can have different influences on temperature from the lower troposphere to the lower stratosphere. Consequently, we focus on the equatorial Indian Ocean and Pacific Ocean areas from the lower troposphere to the lower stratosphere. Moreover, we analyze the thermodynamic reasons behind the response of tropospheric and stratospheric temperature to these two types of El Niño events.

\section{Mechanistic Analysis}

5.1. Dynamic Reasons. The oceans are the main source not only of atmospheric motion, but also of water vapor in the atmosphere. Oceanic changes will contribute greatly to atmospheric circulation and climate change. The northwestern Indian Ocean is surrounded by the African and 


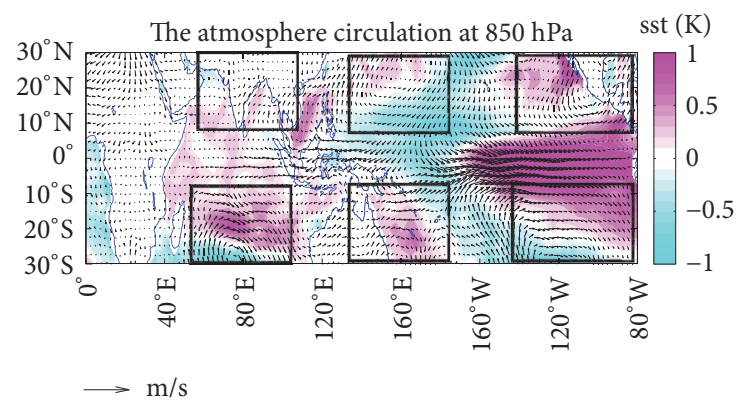

FIgUre 4: Composite wind field (arrows) and SST (color fill) at $850 \mathrm{hPa}$.

Tibetan plateaus, the eastern part of which is the Maritime Continent and western Pacific warm pool, and the southern part reaches Antarctica. As an important part of the AsianAustralian monsoon region, the climate of the Indian Ocean region has distinctive characteristics and rules of variation. Furthermore, the Pacific Ocean provides substantial amounts of sensible and latent heat for the global climate [28]. The tropical Pacific provides the world with the most important interannual variability, known as ENSO [29-31]. From the composite analysis reported in Section 4, we can conclude that the temperature in the lower stratosphere near the Indian and Pacific oceans is significantly affected by the two types of El Niño events. Therefore, using the area over $0^{\circ}-80^{\circ} \mathrm{W}$, and with $850 \mathrm{hPa}$ representing the lower troposphere and $100 \mathrm{hPa}$ representing the lower stratosphere, we focus in this section-again via composite analysis-on investigating the atmospheric circulation pattern and SST differences (SP minus SU) in this area, in the hope that we can explain the dynamic processes involved.

From the composite analysis of the wind field and SST, we can see that, when an SP-type El Niño event occurs, two anticyclonic circulations are stimulated in the lower troposphere $(850 \mathrm{hPa})$ near the oceanic area of the Philippine Islands, as compared to when an SU-type El Niño event occurs (Figure 4). The two anticyclonic circulations are almost symmetric about the equator, which results in the anomalous southeasterly wind in the tropical East Indian Ocean. However, the easterly wind of the anticyclonic circulation begins to converge over the equatorial West Indian Ocean. This is not difficult to understand, since SP-type El Niño events are longer in duration and more intense than SUtype El Niño events.

It is found that the SSTAs in the western Pacific warm pool are cold and the zonal SST gradient weakens, which in turn can weaken the Walker circulation. Originally, the easterly trade winds located on the west side of the eastern Pacific (heating area) weaken or even become westerly winds, which transport the warm water in the western part of the ocean to the eastern part of the anomalous warm water. Consequently, on the west side of the weakened trade winds area, the SST continues to increase and the warm waters of the eastern part of the ocean expand. In turn, the weakening of the easterly winds and strengthening of the westerly winds will continue. The variation in wind direction caused by

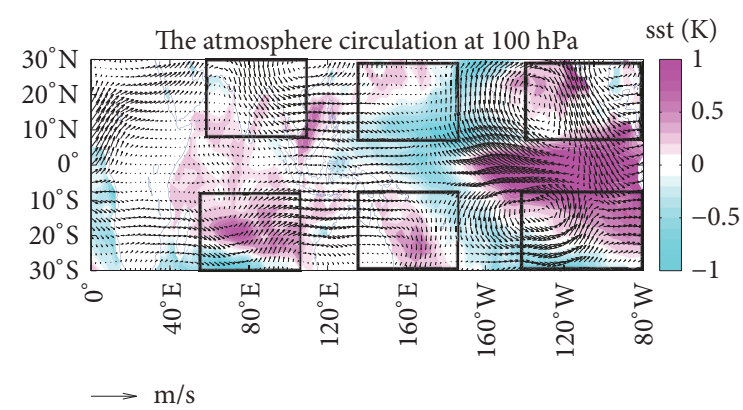

FIGURE 5: Composite wind field (arrows) and SST (color fill) at $100 \mathrm{hPa}$.

the SSTAs induces anomalous divergence in the downward branch of the Walker circulation in the equatorial western Pacific region. Thus, the anomalous anticyclone near the Philippines appears. The model above is called the Gill response (the forced response of atmospheric motion to ocean heat). Because of warmth in the west and the cold in the east, the cold SST in the east stimulates two anticyclonic (Rossby wave-type) circulation anomalies, symmetric about the equator, in the lower troposphere, via a Matsuno-Gilltype circulation response [32]. In the wind field, this presents as an enhancement of the equatorial airflow.

Correspondingly, from $200 \mathrm{hPa}$ (not shown) to $100 \mathrm{hPa}$ (Figure 5), two symmetric cyclone centers are apparent near the oceans of the Philippine Islands and two symmetric anticyclone centers are apparent near the equatorial central Indian Ocean. The stimulated circulation in the upper troposphere over the tropical Indian Ocean is consistent with the response of the atmosphere to the single symmetric heat source. Near the Philippine Islands, the lower layer at $850 \mathrm{hPa}$ is an anomalous anticyclone, while the upper layer at $100 \mathrm{hPa}$ is an anomalous cyclonic circulation. This kind of structure, with an anticyclone in the lower layer and cyclone in the upper layer, contributes to atmospheric descending motion.

In general, near the tropical Indian Ocean, there appears to be a structure comprising a pair of symmetric cyclones from the lower troposphere at $850 \mathrm{hPa}$ and a pair of symmetric anticyclones in the upper troposphere from $200 \mathrm{hPa}$ to $100 \mathrm{hPa}$. This structure is conducive to the transfer of warm air in the lower layer upwards into the upper layer, but not as far as the lower stratosphere.

Besides, near the tropical western Pacific Ocean, there appears to be a pair of symmetric anticyclones in the lower troposphere at $850 \mathrm{hPa}$ and a pair of symmetric cyclones from the upper troposphere from $200 \mathrm{hPa}$ to $100 \mathrm{hPa}$, which favors downward motion. Comparing the occurrence of SP-type and SU-type El Niño events, the SST in this region is colder, which inhibits the cold air in the lower layer moving into the upper layer. Thus, the temperature in the lower stratosphere during an SP-type El Niño event will be warmer.

Moreover, near the tropical eastern Pacific Ocean, there appears to be a pair of symmetric cyclones in the lower troposphere at $850 \mathrm{hPa}$ and a pair of symmetric anticyclones in the upper troposphere from $200 \mathrm{hPa}$ to $100 \mathrm{hPa}$, which is conducive to upward motion. Comparing the occurrence of 
SP-type and SU-type El Niño events, the SST in this region is warmer, meaning this structure favors the transfer of warm air up into the upper layer. Thus, the temperature in the lower stratosphere during an SP-type El Niño event will be warmer.

5.2. Thermodynamic Reasons. In the theory of the vertical propagation of planetary waves, Charney and Drazin [33] pointed out that a Rossby wave can only propagate in westerlies. At the same time, if zonal westerly wind lower than the Rossby critical wind velocity is satisfied, planetary waves (wavenumbers 1 and 2) can transfer to the stratosphere, thereby affecting middle and upper atmospheric circulation systems. According to the theory of wave-current interaction [34], atmospheric density decreases with height and the amplitude of planetary waves increases. Planetary waves will be crushed when transferred to a certain height because of the large amplitude. The resultant release of energy - manifesting as Eliassen-Palm (EP) flux convergence-will result in westerlies dropping and warming the stratosphere. When planetary waves are strong enough, the polar vortex crashes, westerly winds turn easterly, the temperature in the polar regions increases sharply, and the stratosphere suddenly warms $[3,35]$. Under these adiabatic conditions, the cause of acceleration and deceleration of zonal average flow is dependent on the convergence and divergence of EP flux. Therefore, EP flux is usually used as an important tool for diagnosing the propagation of planetary waves. Moreover, in atmospheric circulation research, zonal-mean circulation is most commonly used. According to some studies, Brewer-Dobson circulation will affect lower stratospheric temperature and water $[36,37]$. Thus, it is useful to discuss the variations of Brewer-Dobson circulation and the evolution of atmospheric circulation anomalies caused by wave-current interaction in a quasi-geostrophic approximation at the angle of the zonal mean.

Because the vertical propagation of planetary waves can only happen in the middle and high latitudes and, furthermore, the mid-latitudes are the critical area for planetary waves transferring upwards from the troposphere to the stratosphere $[38,39]$, the area over $45^{\circ}-60^{\circ} \mathrm{N}$ is chosen to analyze the representative part of the heat flux. The term $\overline{v^{\prime} T^{\prime}}$ can be used to quantify the heat flux, and as a criterion of EP flux [40], where $v^{\prime}$ stands for the zonal deviation of southerly and northerly wind and $T^{\prime}$ for the zonal deviation of temperature. If $\overline{v^{\prime} T^{\prime}}>0$, it means that the heat flux is positive, the EP flux increases, and the Brewer-Dobson circulation enhances. If $\overline{v^{\prime} T^{\prime}}<0$, it means that the heat flux is negative, the EP flux decreases, and the Brewer-Dobson circulation attenuates.

In this study, ERA-Interim data are used, including the $2.5^{\circ} \times 2.5^{\circ}$ daily meridional wind field and temperature field. Moreover, $200 \mathrm{hPa}$ stands for the upper troposphere, $100 \mathrm{hPa}$ for the lower stratosphere, and $50 \mathrm{hPa}$ for the middle stratosphere. From the heat flux composites of the SP-type and SUtype El Niño events from 1978 to 2016 in Table 2, the total composite value is a significantly negative anomaly at $200 \mathrm{hPa}$ and $50 \mathrm{hPa}$; however, it is not significantly positive at $100 \mathrm{hPa}$. In addition, the value at $200 \mathrm{hPa}$ and $100 \mathrm{hPa}$ in December
TABLE 2: Composite heat fluxes of SP- and SU-type El Niño events during 1978-2016 (units: mK/s).

\begin{tabular}{lccc}
\hline Height & $200 \mathrm{hPa}$ & $100 \mathrm{hPa}$ & $50 \mathrm{hPa}$ \\
\hline Total value & -1.64 & $0.13^{*}$ & -2.25 \\
Dec. value & 14.61 & 12.88 & -3.19 \\
Jan. value & -8.61 & -5.02 & $-0.53^{*}$ \\
Feb. value & -10.91 & -7.49 & -3.02 \\
\hline
\end{tabular}

${ }^{*}$ Not significant at the $95 \%$ confidence level.

is positive compared to January and February. Basically, the Brewer-Dobson circulation in December is not significant [41]. Without consideration of the heat flux in December, the heat flux composition in the upper troposphere and lower stratosphere from $200 \mathrm{hPa}$ to $50 \mathrm{hPa}$ exhibits an overall negative anomaly (data not shown).

In general, comparing the occurrence of SP-type and SUtype El Niño events, as shown in Table 2, $\overline{v^{\prime} T^{\prime}}<0$, which means the heat flux is negative, the EP flux decreases, and the Brewer-Dobson circulation attenuates. It is easy to explain this point. Comparing the occurrence of SP-type and SUtype El Niño events, a cold anomaly exists in the tropical Pacific Ocean and there is a decrease in planetary waves. Correspondingly, the drifting of gravity waves decreases in the tropical stratosphere. According to "downward control theory," the Brewer-Dobson circulation in the stratosphere decreases. By adiabatic cooling, the negative anomaly will heat the lower stratosphere at low latitudes and cool the upper stratosphere at middle latitudes.

\section{Summary}

Through composite analysis of the temperature from the lower troposphere to the lower stratosphere under the conditions of SP- and SU-type El Niño events and investigation of the thermodynamic and dynamic mechanisms involved, we conclude the following:

(1) SP-type El Niño is a much stronger and more durable phenomenon than SU-type El Niño. The positive SSTAs during SP-type events persist for about 14 to 16 months, whereas they only persist for about 8-10 months during SU-type events. In addition, the eastwest SST gradient is much weaker than during SPtype events.

(2) Through composite analysis of the temperature from the lower troposphere to the lower stratosphere, different characteristics in the lower and higher layers are apparent. In the lower troposphere, the temperature anomaly near the Indian Ocean region shows a significant positive anomaly that is symmetric about the equator, whereas, in the lower stratosphere, the temperature anomaly shows a negative anomaly that is symmetric about the equator. However, in the area $30^{\circ} \mathrm{N}$ and $30^{\circ} \mathrm{S}$ of the equator, most of the lower stratosphere features a statistically significant positive anomaly. This indicates that, apart from the equatorial Indian Ocean region, SP-type El Niño events are more 
conducive than SU-type events to warming the lower stratosphere.

(3) Through composite analysis of the wind field and SST, the atmospheric circulation pattern is found to be consistent with a Matsuno-Gill-type response. Near the tropical Indian Ocean, the atmospheric circulation structure benefits the transfer of warm air in the lower layer upwards into the upper layer, but not as far as the lower stratosphere.

(4) Near the tropical western Pacific Ocean, the atmospheric circulation structure is conducive to downward motion. Comparing the occurrence of SP-type and SU-type El Niño events, the SST near this region is colder, which inhibits the movement of cold air in the lower layer upwards into the upper layer.

(5) Near the tropical eastern Pacific Ocean, the atmospheric circulation structure favors upward motion. Comparing the occurrence of SP-type and SU-type El Niño events, the SST near this region is warmer, which is beneficial for the upward transfer of warm air into the upper layer.

(6) Comparing the occurrence of SP-type and SU-type El Niño events, the heat flux is negative, the EP flux decreases, and the Brewer-Dobson circulation decreases, making the temperature higher in the upper tropospheric and lower stratospheric region of the low latitudes.

\section{Conflicts of Interest}

The authors declare that there are no conflicts of interest regarding the publication of this paper.

\section{Acknowledgments}

This work was supported by the Program of the National Natural Science Foundation of China (41675039, 41375047, and 91537213) and Guangdong Ocean University Research Support Funding for Air-Sea Interaction and Data Assimilation. The authors appreciate greatly $\mathrm{Dr}$. Jianjun $\mathrm{Xu}$ for his good suggestions in the processing of the manuscript revision.

\section{References}

[1] P. Haynes, T. Shepherd, and V. Wirth, "Report on the SPARC tropopause workshop," Sparc Newsletter, vol. 17, pp. 3-10, 2001.

[2] S. G. H. Philander, "El Niño southern oscillation phenomena," Nature, vol. 302, no. 5906, pp. 295-301, 1983.

[3] C. H. Lu and Y. H. Ding, "Progress in the study of StratosphereTroposphere Interaction," Advances in Meteorological Science and Technology, vol. 3, no. 2, pp. 6-21, 2013.

[4] A. W. Brewer, "Evidence for a world circulation provided by the measurements of helium and water vapour distribution in the stratosphere," Quarterly Journal of the Royal Meteorological Society, vol. 75, no. 326, pp. 351-363, 1949.

[5] R. Ren, G. Wu, M. Cai, S. Sun, X. Liu, and W. Li, "Progress in research of stratosphere-troposphere interactions: application of isentropic potential vorticity dynamics and the effects of the Tibetan Plateau," Acta Meteorological Sinica, vol. 72, no. 5, pp. 853-868, 2014.

[6] B. Chen, X. D. Xu, J. C. Bian et al., "Sources, pathways and timescales for the troposphere to stratosphere transport over Asian Monsoon Regions in boreal summer," Chinese Journal of Atmospheric Sciences, vol. 34, no. 3, pp. 495-505, 2010.

[7] M. Taguchi and D. L. Hartmann, "Increased occurrence of stratospheric sudden warmings during El Niño as simulated by WACCM," Journal of Climate, vol. 19, no. 3, pp. 324-332, 2006.

[8] C. D. Camp and K.-K. Tung, "Stratospheric polar warming by ENSO in winter: a statistical study," Geophysical Research Letters, vol. 34, no. 4, Article ID L04809, pp. 545-559, 2007.

[9] K. S. Gage and G. C. Reid, "Longitudinal variations in tropical tropopause properties in relation to tropical convection and el nifio-southern oscillation events," Journal of Geophysical Research: Oceans, vol. 92, no. 13, pp. 14197-14203, 1987.

[10] G. C. Reid, K. S. Gage, and J. R. McAfee, "The thermal response of the tropical atmosphere to variations in equatorial Pacific sea surface temperature," Journal of Geophysical Research: Atmospheres, vol. 94, no. D12, pp. 14705-14716, 1989.

[11] E. Yulaeva, J. R. Holton, and J. M. Wallace, "On the cause of the annual cycle in tropical lower-stratospheric temperatures," Journal of the Atmospheric Sciences, vol. 51, no. 2, pp. 169-174, 1994.

[12] W. H. Quinn, V. T. Neal, and S. E. A. De Mayolo, "El Niño occurrences over the past four and a half centuries," Journal of Geophysical Research: Oceans, vol. 92, no. 13, pp. 14449-14461, 1987.

[13] S. Wang, "Reconstruction of El Niño event chronology for the last 600 year period," Journal of Meteorological Research, vol. 6, no. 1, pp. 47-57, 1992.

[14] D. B. Enfield and C. S. Luis, "Low-frequency changes in El NiñoSouthern Oscillation," Journal of Climate, vol. 4, no. 12, pp. 11371146, 1991.

[15] C. Fu, H. F. Diaz, and J. O. Fletcher, "Characteristics of the response of sea surface temperature in the central pacific associated with warm episodes of the southern oscillation," Monthly Weather Review, vol. 114, no. 114, pp. 14-15, 2000.

[16] T. P. Barnett, "The interaction of multiple time scales in the tropical climate system," Journal of Climate, vol. 4, no. 3, pp. 269-285, 2009.

[17] T. Yasunari, "Zonally propagating modes of the global east-west circulation associated with the southern oscillation," Journal of the Meteorological Society of Japan, vol. 63, no. 6, pp. 1013-1029, 2007.

[18] B. Wang, "Interdecadal changes in El Niño onset in the last four decades," Journal of Climate, vol. 8, no. 2, pp. 267-285, 1995.

[19] J. Xu and J. C. L. Chan, "The role of the Asian-Australian Monsoon System in the onset time of El Niño events," Journal of Climate, vol. 14, no. 14, pp. 169-174, 2001.

[20] Y. Hu and L. Pan, "Arctic stratospheric winter warming forced by observed SSTs," Geophysical Research Letters, vol. 36, no. 11, pp. 163-182, 2009.

[21] F. Xie, J. Li, W. Tian et al., "Signals of El Niño Modoki in the tropical tropopause layer and stratosphere," Atmospheric Chemistry and Physics, vol. 12, no. 2, pp. 3619-3653, 2012.

[22] I. Zubiaurre and N. Calvo, "The El Niño-Southern Oscillation (ENSO) Modoki signal in the stratosphere," Journal of Geophysical Research Atmospheres, vol. 117, no. 4, Article ID D04104, 2012. 
[23] R. W. Spencer and J. R. Christy, "Precision and radiosonde validation of satellite gridpoint temperature anomalies. part Ii: a tropospheric retrieval and trends during 1979-90," Journal of Climate, vol. 5, no. 8, pp. 847-857, 1992.

[24] M. Liao, P. Zhang, X. B. Wu et al., "Research advances of the temperature changes in upper air using Msu time series," Meteorological Monthly, vol. 37, no. 9, pp. 1151-1157, 2011.

[25] Z. Sun and Y. Zeng, "Composite analysis of relation of january surface temperature anomaly in china to northern 500hpa height abnormality," Journal of Nanjing Institute of Meteorology, vol. 18 , no. 4, pp. 471-477, 1995.

[26] H. Xu, J. He, and B. Zhou, "Composite analysis of summer monsoon onset process over south china sea," Journal of Tropical Meteorology, vol. 17, no. 1, pp. 10-22, 2001.

[27] L. P. Li, P. X. Wang, H. Li et al., "Analysis of interdecadal anomaly relations between sub-surface sea temperature and sea level pressure over the north pacific," Journal of Tropical Meteorology, vol. 19, no. 4, pp. 357-366, 2003.

[28] M. A. Cane, “A role for the tropical Pacific," Science, vol. 282, no. 5386, pp. 59-61, 1998.

[29] E. M. Rasmusson and T. H. Carpenter, "Variations in tropical sea surface temperature and surface wind fields associated with the Southern Oscillation/El Niño," Monthly Weather Review, vol. 110, no. 5, pp. 354-384, 1982.

[30] J. Holton, R. Dmowska, and S. Philander, El Niño, La Niña, and the Southern Oscillation, Academic Press, Salt Lake City, Utah, USA, 1989.

[31] K. E. Trenberth, “The Definition of El Niño," Bulletin of the American Meteorological Society, vol. 78, no. 12, pp. 2771-2777, 1997.

[32] A. E. Gill, "Some simple solutions for heat-induced tropical circulation," Quarterly Journal, vol. 106, no. 449, pp. 447-462, 1980.

[33] J. G. Charney and P. G. Drazin, "Propagation of planetaryscale disturbances from the lower into the upper atmosphere," Journal of Geophysical Research, vol. 66, no. 1, pp. 83-109, 1961.

[34] D. G. Andrews, J. R. Holton, and C. B. Leovy, Middle Atmosphere Dynamics, Academic San Diego, California, Calif, USA, 1987.

[35] G. Yang, C. Li, and L. Li, "Advance in research on stratospheric sudden warming and its influences," Journal of the Meteorological Sciences, vol. 32, no. 6, pp. 694-708, 2012.

[36] C. Shi, D. Guo, and J. Xu, "The latitudinal structure of recent changes in the boreal Brewer-Dobson circulation," Atmospheric Chemistry Physics, vol. 15, no. 17, pp. 24403-24417, 2015.

[37] C.-H. Shi, B. Zheng, Y.-J. Chen, and Y. Bi, “The quasi-biennial oscillation of water vapor in tropic stratosphere," Chinese Journal of Geophysics, vol. 52, no. 10, pp. 2428-2435, 2009.

[38] Y. Harada, A. Goto, H. Hasegawa, N. Fujikawa, H. Naoe, and T. Hirooka, "A major stratospheric sudden warming event in January 2009," Journal of the Atmospheric Sciences, vol. 67, no. 6, pp. 2052-2069, 2010.

[39] K. Kodera, H. Mukougawa, and A. Fujii, "Influence of the vertical and zonal propagation of stratospheric planetary waves on tropospheric blockings," Journal of Geophysical Research Atmospheres, vol. 118, no. 15, pp. 8333-8345, 2013.

[40] A. Solomon, "Wave activity events and the variability of the stratospheric polar vortex," Journal of Climate, vol. 27, no. 20, pp. 7796-7806, 2014.

[41] Q. L. Chen and Y. J. Chen, "Stratospheric residual circulation and its temporal and spatial evolution," Chinese Journal of Atmospheric Sciences, vol. 31, no. 1, pp. 137-144, 2007. 

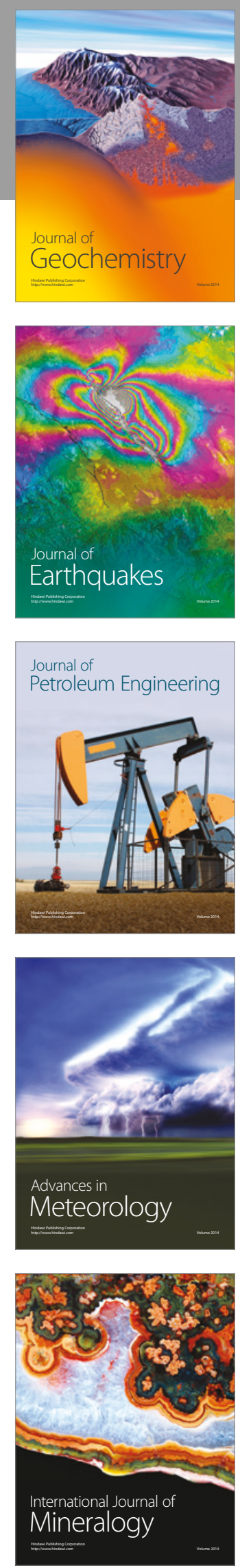
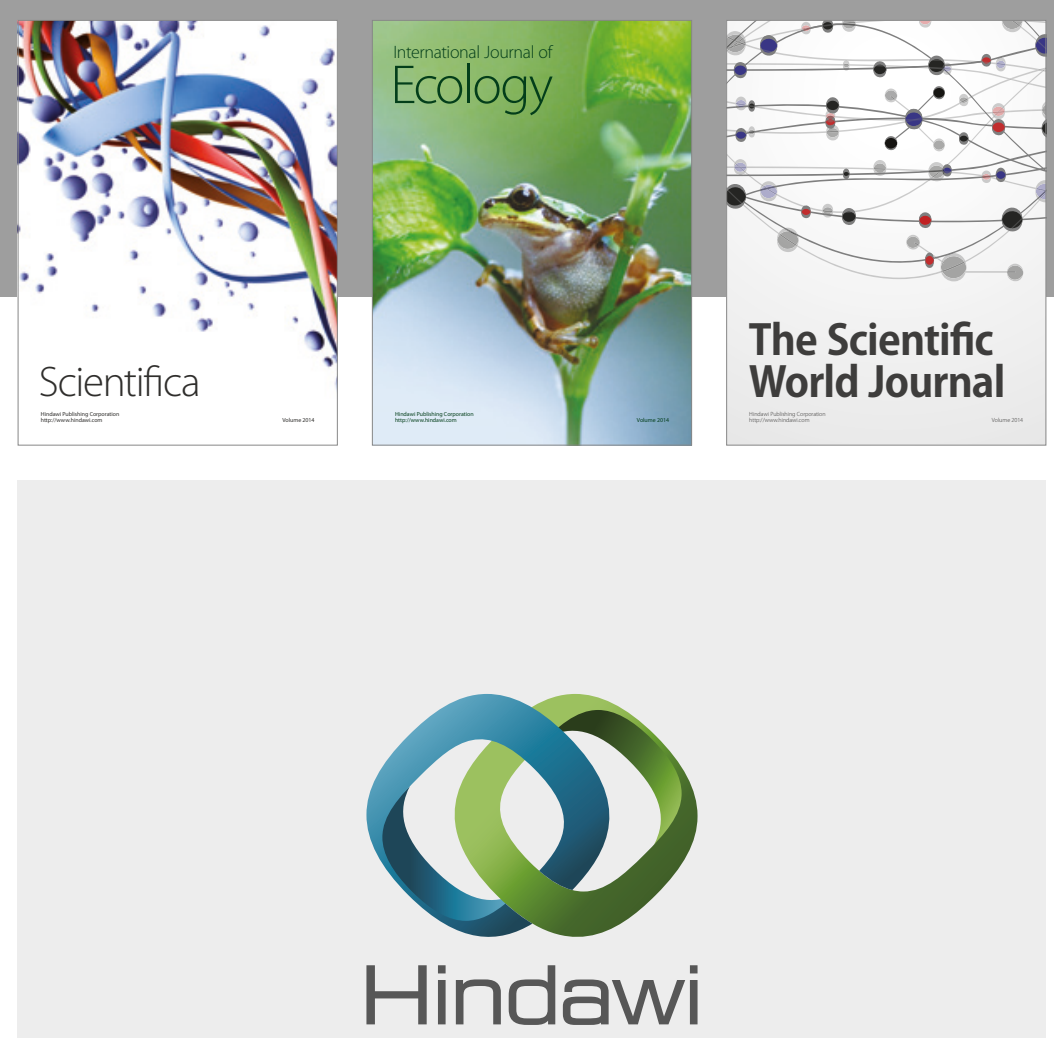

Submit your manuscripts at

https://www.hindawi.com
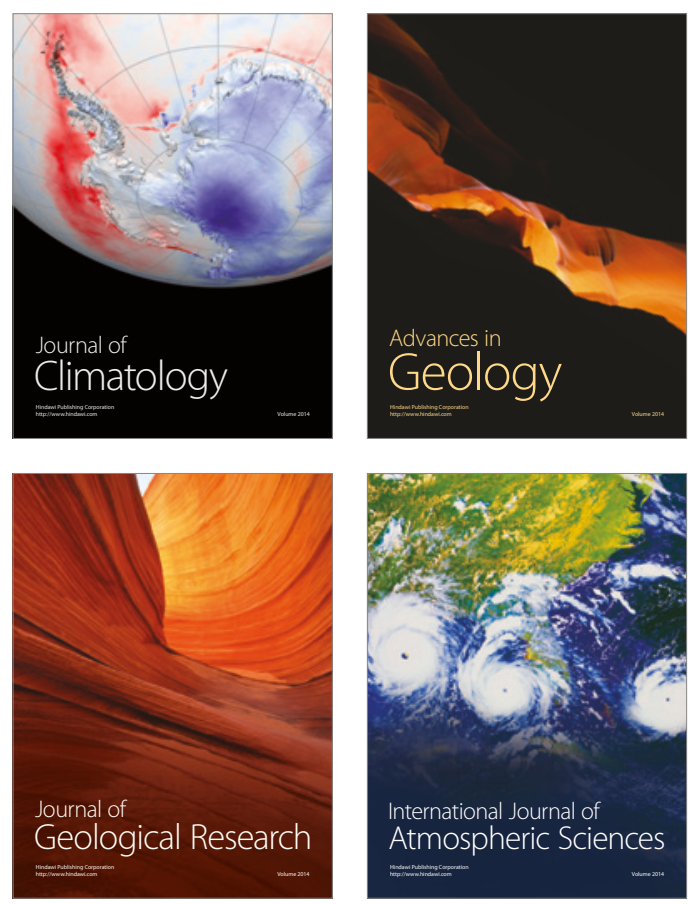

The Scientific

World Journal
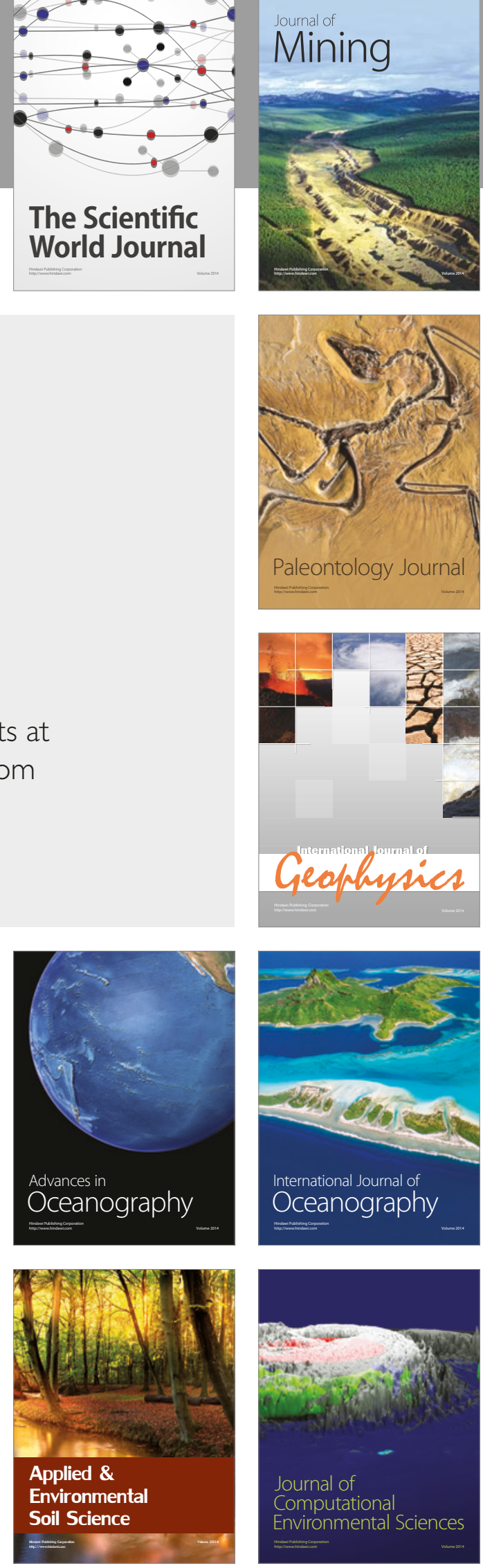